\section{THE CALCANEO-FIBULAR LIGAMENT AND ITS NEIGHBORHOOD, BASED ON DISSECTIONS.}

BY EDWARD A. TRACY, M.D., BOSTON,

Orthopedic Surgeon to Mt. Sinai Hospital.

The calcaneo-fibular ligament is the middle fasciculus of the external lateral ligament of the ankle-joint. It is variously and erroneously pictured and described in most of the anatomical textbooks, as the following examples show: Quain ${ }^{1}$ describing it writes: "It descends from the extremity of the fibula to the external surface of the os calcis." 'In the same book it is incorrectly pictured in Fig. 218 (a posterior view) as being attached to the inside surface of the lower end of the fibula, and again incorrectly in Fig. 222 as arising from the lower end of the fibula.

In Gray ${ }^{2}$ it is likewise incorrectly pictured in Fig. 264 and inaccurately described as arising "from the apex of the external malleolus."

Cunningham ${ }^{3}$ pictures the ligament incorrectly in Fig. 229 and inaccurately describes it as "attached by one end to the front of the tip of the external malleolus."

Deaver," writing of this ligament, describes it as " cord-like and long; it extends from the apex of the "external malleolus to the external surface of the os calcis." $\mathrm{He}$ pictures it as arising in a discursive manner from the lateral and anterior surface of the lower end of the fibula.

Gerrish $^{5}$ pictures correctly the origin of the calcaneo-fibular ligament (in a plate copied from Testut), but somewhat inaccurately describes it in the text as " descending slightly backwards from the tip and the forepart of the outer surface of the external malleolus to the middle surface of the os calcis."

$\mathrm{His}^{6}$ in Fig. 264 pictures the calcaneo-fibular ligament with too discursive an origin. In the text he describes it thus: "The calcaneo-fibular ligament stretches as a roundish cord from the point of the malleolus obliquely downwards and backwards to the lateral surface of the calcaneus; its outer surface forms a shallow furrow, in which the peroneal tendons glide."

Carl Todt ${ }^{7}$ in Fig. 484 correctly pictures this ligament.

Testut ${ }^{8}$ pictures the calcaneo-fibular ligament correctly and describes it as " attached in front of the summit of the external malleolus. From there it passes obliquely downwards and backwards to its attachment on the external surface of the calcaneum. Superficially it is crossed almost at right angles by the tendons of the lateral peroneal muscles."

The only anatomical works that I have found to correctly picture and describe (so far as they go) the calcaneo-fibular ligament are Anatomie Humaine par Poirier et Charpy, ${ }^{\circ}$ and Traité

\footnotetext{
1 London edition, 1899.

2 New York, 1896

New York, 1902 .

S Surgical Anatomy,

5 Philadelphia, 1902.

7 Atlas of Human Anatomy, N. Y., 1899.

8 Paris, 1899.
}

d'Anatomie Humaine, par Testut ${ }^{10}$ quoted above.

Poirier et Charpy's text reads: "The calcaneofibular ligament, a flattened cord about 3 to $4 \mathrm{~cm}$. long and $5 \mathrm{~mm}$. in circumference, is attached, not to the point of the fibula, but, as I have demonstrated, to the anterior border and the external surface of the malleolus, near its summit, upon which it is reflected and passes almost horizontally backwards and downwards to the external surface of the os calcis, where its attachment leaves an imprint upon the dried bone."

None of the anatomists have described this ligament adequately. Its origin is not from the summit, apex or tip of the lower end of the fibula. It arises above this point on the anterior surface of the malleolus. Its direction is not fixed, as one would infer by reading the above anatomists, but varies with the position of the foot. With the foot at right angles to the leg, its direction is downwards and backwards, but with the foot in the position of complete extension, the calcaneofibular ligament is directly backwards and I have seen an anatomical teacher mistake it for the posterior fasciculus of the external lateral ligament, with the foot in this position. The German anatomist His has described its outer surface as forming a shallow furrow in which the peroneal tendons glide. This is true with the foot in the ordinary position midway between extension and flexion, but with the foot inverted, extended or strongly flexed, the calcaneo-fibular ligament is tensed and it becomes a straight cord without a furrow, lifting the peroneal tendons (brevis and longus) backward and outward from their usual course.

So much for the calcaneo-fibular ligament itself. I will add a description of the peroneal tendons (in part), their common sheath and the external annular ligament, all in the immediate vicinity of the calcaneo-fibular ligament. This description is based upon a considerable number of dissections (adult subjects only). The description applies to the leg in an upright position, the toes being forward. The tendons of the peroneus longus and the peroneus brevis muscles pass back of the outer ankle-bone surrounded by their common sheath. This common sheath enwraps the tendons from its origin in the fascia of the lateral peronei muscles to about one-half inch below the lower end of fibula, to where the tendons enter separate sheaths. It covers, in common, both tendons, except a small space where the sheath is wanting at the lower end of the fibula, allowing the uncovered tendons to travel over the polished lining of the bone. The lower end of the peroneus brevis muscle is intimately connected with the common sheath of the tendons, its fibers often reaching to a level near the lower end of the fibula. This lower portion of this muscle acts, I believe, as a tensor for the sheath serving to keep the sheath folds from being caught between the tendons and the surfaces they press upon. Fairly often (found in 11 out of 28 ankles dissected) there is a third tendon in the common 
sheath, arising from a muscle attached to the fibula at various heights and inserted into the peroneal spine of the os calcis. ${ }^{11}$

The lower portion of the fibula, over which the tendons of the peroneus brevis and peroneus longus play (the portion bare of covering of the common sheath) is termed, in the books, the groove for the peroneal tendons. It can more correctly be described as a flanged surface against which the tendons partly press; it is not a groove or hollowed channel in which the tendons safely play. Actually this flanged surface of the fibula forms a part of the outer wall of the groove or trough, through which the tendons pass, the remainder of the outer wall of the trough being formed by the external annular ligament, and this trough is a variable quantity in the same subject, i. e., it varies in size with the position of the foot. This variation in the size of the tendon trough or groove depends upon the tenseness of the calcaneofibular ligament.

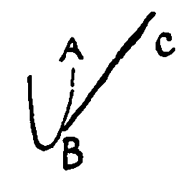

Fig 1 .

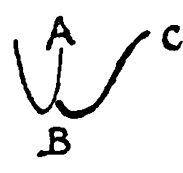

Fig 2 .
Fig. 1. $A, B, C$. Tendon trough with calcaneo-fibular ligament tensed.

FIG. 2. $A, B, C$. Tendon trough with calcaneo-fibular ligament relaxed.

That this variation is considerable is shown in Fig. 1 and Fig. 2, taken from two casts of the peroneal tendon trough; Fig. 2 showing the trough with the foot at right angles to the leg, the calcaneo-fibular ligament relaxed, Fig. 1 showing the same tendon trough with the foot extended and abducted, thus tensing the calcanco-fibular ligament and lessening the tendon trough or groove.

By this tensing of the calcaneo-fibular ligament (the foot extended and abducted), the peroneal tendons are lifted backwards and outwards, upon the tensed ligament, in such wise that the peroneus longus tendon rests externally upon the external annular ligament.

The external annular ligament extends from the inferior and posterior borders of the external surface of the lower one-half inch (or more) of the fibula, backward and downward to be inserted by several strong fasciculi into the os calcis, back of the middle point of the external surface of this bone. It is intimately connected with that portion of the common sheath of the tendons underlying it. This external annular ligament differs in strength in different subjects. In some it is of a dense fibrous structure, one sixteenth of an inch thick at its juncture with the lower end of the fibula; in most cases there is a marked thickening of crossed (reinforced) fibers at this point; in all cases it is remarkable strong.

11 This muscle, called the peroneus quartus and also the peroneus calcis (a better name would be that suggested by Thayer - peroneus posticus), I am inclined to regard as an example of reversion, though it is not mentioned as such in Darwin's "Descent of Man."
The tendons of the peroneal (longus and brevis) muscles, having passed through the trough or groove above described, and afterward, through a half inch of loose envelopments in the common sheath, then enter into separate sheaths of strong fibrous structure, firmly bound down to the underlying bones. The tendon of the peroneus longus enters its sheath at a point about a half inch away from the lower point of the anklebone (forward and downward), and continues downward and forward, grooving the external surface of the cuboid, and continuing in the deep groove on the under surface of this bone and across the deep tissues of the foot, to be inserted into the outer side of the base of the first metatarsal and into the internal cuneiform. The tendon of the peroneus brevis enters its separate sheath, situated above that of the peroneus longus, and courses through its sheath downward, outward and forward to be inserted into the outer and back surface of the base of the fifth metatarsal.

The points where the separate tendons enter each sheath are fixed points; these points, however, vary thpir relations to the common channel for the tendons back of the ankle-bone in accordance with the position of the foot. With the foot inverted, the tendons at their entrance to their separate sheaths travel in a plane internal to that in which they travel just back of the anklebone. When the foot is extended, combined with abduction, the fixed points where the tendons enter their separate sheaths are in a plane that is external to the plane in which the tendons travel back of the ankle-bone.

The practical bearings of this investigation in the anatomy of the outer ankle-bone region are its elucidation of the mechanism of the dislocation of the peroneal tendons that occasionally takes place (the tendons leaving their trough above described and slipping over the lower end of the malleolus) and its indications for the correct surgical treatment of this condition when it occurs.

From what has been described it can be understood how tensing the calcaneo-fibular ligament lessens the groove or trough through which pass the peroneal longus and brevis tendons back of the ankle-bone, thus forcing the longus tendon against the annular ligament; how making the plane of action of the tendons in their separate sheaths external to the plane of action of the same tendons back of the anklebone causes the tendons to press against the annular ligament as when the foot is extended and abducted; how the variations noted in the strength of the annular ligament determine its tearing or not (Kraske showed how the annular ligament must be torn before the tendons escape over the ankle-bone).

The practical bearing of this investigation in regard to the correct surgical treatment of dislocation of the peroneal tendons is that the deepening of the groove in the fibula (taught in surgical textbooks by Cheyne and Burchard, ${ }^{12}$

12 Manual of Surgical Treatment. Phila., 1900, vol. xx, p. 237. 
Tillmans, ${ }^{13}$ Whitman ${ }^{14}$ and Monks ${ }^{15}$ ), is unsound, because the groove of the fibula is not designed for the safe play of the tendons, is only a small part of the tendon trough; it is shallow normally, and we cannot improve on nature's normal forms.

On the other hand, the correct surgical treatment for dislocation of the peroneal tendons is the surgical reconstruction of the external annular ligament (as done and described by Kraske ${ }^{16}$ ), and keeping the foot until healing takes place in such a position that the calcaneo-fibular ligament is relaxed. This position is that between extension and flexion.

\section{A CASE OF PSEUDO-HERMAPHRODITISM.*}

BY William L. HaRris, M.D., PROVIdence, R. I., Surgeon to St. Joseph's Hospital.

The crowning infamy of the Roman Emperor Nero's career of degeneracy was, according to the historian Suetonius, his marriage with the boy Sporus. ${ }^{1}$ It was a very public affair and well advertised throughout the city. Some sort of operation was performed on the boy and the historian says an attempt was made to alter him into a woman. Even in the terror of the tyrant's reign the wags of the city gave currency to the observation that Nero's father would have done well for mankind had he taken unto himself such a wife.

This well-known story from ancient history is too gossipy, also too lacking in details, for us to hazard a guess as to the operation the crude surgery of the years between 60 and 70 A.D. was capable of performing, or even as to the physical condition of the boy Sporus. But it has been suggested to me by the subject which shall be my theme this evening and the part $\mathrm{I}$. once played quite unwittingly and unwillingly, and against my protest, in the mating of two males.

It is now some years ago since I was called one night towards midnight to a patient, a girl some seventeen years old, who, I was told, was " having a fit." Her family were people in very comfortable circumstances and patients of mine. I hastened to the call and found them quite unprepared for my sudden arrival. The mother pointed out the room of the sick girl, but asked me to wait till she herself was fully dressed. Quite absent mindedly I disregarded the woman's injunction and pushed my way in the dark to the half open door. It would be difficult to describe the shock I received as I entered. The girl was lying on the bed evidently unconscious, but in the writhings produced by the convulsion she was almost completely uncovered; and my attention was immediately attracted by the presence of an unusually developed penis some six inches long and perhaps three inches in circumference. But my curiosity to examine more closely this unusual

13 Text-book of Surgery. N. Y., 1899, p. 510

14 Treatise on Orthopedic Surgery. N. Y 1901, p. 555.

1 International Text-book of Surgery. Phila., 1900, p. 758.

16 Centralbl. f. Chir., No. 24, 1895 .

* Read before the Fall River Medical Society, Dec. 8, 1908. 1 See Suetonius, chapter 27. condition of affairs was cut short by the appearance of the mother, now thoroughly embarrassed and crestfallen that what was evidently a family secret had been exposed to me. The patient's condition was not serious and yielded to the usual treatment. But afterwards I could not refrain from discussing with her parents the extraordinary phenomenon displayed by this alleged girl.

From them I discovered that when the child was born there was evident a small, imperforate protrusion in the genital region which the attending physician described as an enlargement of the clitoris. Immediately below its base and in the median line there was a small opening about one inch long, through which the child voided urine. The physician's explanation was accepted and in a few days the infant was named after a female relative and entered on the rôle of a girl. With the growth of the girl, the mysterious protuberance also grew. The physicians who were consulted always agreed with the first and allayed the fears of the parents. When the child was ten, the mother several times noticed that at night this mass would become quite erect, but, secure in the consultations of earlier years, she kept her knowledge to herself and consulted no further.

The child grew up as a girl and entered into the games of girls, being very fond of dolls. Household work she abominated, as, for that matter, many a girl of undoubted sex abominates it nowadays. Her companions, especially as she grew older, were not those of her own age but older women who were very fond of her and with whom she sometimes stayed over night. Her features were somewhat coarse, her voice deep and harsh, her upper lip and chin had a considerable growth of black hair, while the hair of her head was decidedly coarse and abundant. She had two sisters younger than herself, but felt a marked aversion to helping her mother in caring for them. At fifteen both parents remarked a great change in her. She had been attending school till then and was considered a good scholar. But at that age she begged so hard to be allowed to go to work that her parents consented and she was soon employed in an industrial establishment. Her ambition was to own a bicycle and she soon had saved enough money to buy one. She speedily became proficient in its use and her performances on it were the talk of the neighborhood. She could ride the fastest and the farthest of any of her companions.

At seventeen she was seized with her first attack of epilepsy. In what was probably the third or fourth attack I was summoned.

All that I heard and saw whetted my appetite to know more about the case, which was unique in my experience. The text and reference books mention such cases but sparingly and in general practice they come seldom if ever. At my earnest request to determine if possible the sex of the patient, the parents consented and Dr. J. W. Mitchell; of Providence, and I made a careful examination under ether. We found the patient fairly well nourished, with muscles well developed. There was no increase of fat or glandular tissue 